\title{
Finite Element Calculation of Residual Thermal Stresses for Functionally Graded Hydroxyapatite-Titanium Plate Design
}

\author{
${ }^{* 1}$ Siti Nur Sakinah Jamaludin, ${ }^{2}$ Faizal Mustapha, ${ }^{1}$ Dewan Muhammad Nuruzzaman, ${ }^{3}$ Tuan Muhammad Yusoff Tuan \\ Ya, and ${ }^{1}$ Shahnor Basri \\ *1Faculty of Manufacturing, Universiti Malaysia Pahang, 26600 Pekan, Pahang, Malaysia \\ ${ }^{2}$ Department of Aerospace Engineering, Universiti Putra Malaysia, 43400, Serdang, Selangor, Malaysia \\ ${ }^{3}$ Faculty of Mechanical Engineering, Universiti Malaysia Pahang, 26600 Pekan, Pahang, Malaysia
}

*Corresponding author: Address: Faculty of Manufacturing Engineering, Universiti Malaysia Pahang, 26600 Pekan, Pahang, MALAYSIA. E-mail address: snursakinah@gmail.com, Phone: +60139012376 Fax: +6095493323

\begin{abstract}
:
Functionally graded materials (FGMs) have varying graded composition along their thickness as the result of a gradual transition of the properties belongs to the different composed materials. Whenever these two dissimilar materials are combined together, the residual stress caused certainly by the difference of coefficient of thermal expansion will leads to decohesion/delamination of the structures. This study aims to analyze the residual thermal stress for the design of functionally graded Hydroxyapatite-Titanium plate as a solution to the sharp interfaces. Finite element method (FEM) has been implemented for the parametric study to see the correlation between some parameters and the performance of the FGM structure. The results show that $\mathrm{P}=1, \mathrm{t}= \pm 0.8 \mathrm{~mm}$ and $\mathrm{N} \geq 5$ are the optimized and the best values for the compositional distribution exponent, thickness of the graded layers and the layer number, respectively. The calculated residual thermal stress values were verified through the comparison with the established results reported previously. In conclusion, the FEM is proved applicable for the design and evaluation of elastic residual thermal stress of an FGM structure.
\end{abstract}

Key words: Functionally graded material, Hydroxyapatite-Titanium, residual thermal stress, finite element method

\section{Introduction}

The notion of FGMs was brought into inception in early 90's in Japan as a means of mitigating issues concerning thermal barrier coatings in the aerospace industry [1]. The development of this relatively new class of materials was then further extended to other fields of applications including nuclear fast breeder and fusion reactors [2], bio-medical engineering [3] and thermoelectric as well as piezoelectric devices $[4,5]$ due to its phenomenological properties. FGMs are essentially a new class of advanced multifunctional composites that comprises volume fractions of constituent materials varied spatially which in turn provides a non-uniform microstructure with graded properties [6]. The gradients produced may be tailored to meet desired requirements whilst providing the best utilization of composite components. This technology has somewhat mitigate performance issues arises from abrupt transitions between dissimilar materials viz. sharp interfaces due to joining via adhesion which induces substantial mechanical as well as thermal stresses [7]. Therefore, optimal fabrication process in which combination of

Doi:10.5505/apjes.2013.10820 
several methods depending on the properties of the constituent materials must be implemented. The best combination will demonstrate the preservation on the quality of the fabricated FGM whilst ultimately reduce the entire production costs.

For FGMs structures, the cooling process from the fabrication temperature leads to the generation of thermal residual stresses due to the differences in elastic and thermal properties of the different materials. In order to produce a high performance FGM without any crack or failure within the FGM adjacent layers, it is important to make sure that the residual thermal stresses are smoothly distributed in gradual change. Accordingly, this paper aims to analyze and search for the optimum distribution of composition and microstructure in FGMs before fabrication. Previously, there are some numerical studies of thermal stress using finite element method (FEM) performed in order to find the optimum design of FGMs structures.

Many recent studies on the importance of joining two different materials while simultaneously eliminating

\section{Finite Element Analysis}

In the analysis on the HA/Ti FGM thermo-fluid behavior, the finite element method was applied for the computer simulation of the residual thermal stresses. As shown in Figure 1, the three dimensional (3-D) cylindrical shape of the FGM is transferred into two dimensional (2-D) ax symmetric model based on its original shape and coordinate systems. Subsequently, the residual thermal stresses analysis was carried out using ANSYS 14.0 by assuming the two materials phases were ideally joined and or minimizing the sharp interfaces within the structures have been reported for the development of high quality FGMs. In the optimum design of FGMs, FEM) has becomes among the famous implementation for the modeling study of the FGMs' thermal stresses. Park et al. has presented a crack-free joint between $\mathrm{Al} 2 \mathrm{O} 3$ and $\mathrm{Ni}$ material which produced by controlling the composition of the inter-layers and optimizing the dispersion process [8]. The work was inspired by the study made by Lee et al. who demonstrated the joining of two ceramic materials which is $\mathrm{Si} 3 \mathrm{~N} 4$ and $\mathrm{Al} 2 \mathrm{O} 3$ using sialon polytypoid functional gradient joining. In the achievement, 15 layers of Si3N4-A12O3 FGM were obtained as the optimum number of layers for the materials combination [9]. The similar research direction also have been aimed by Sarikaya and Chen et al. who investigated residual thermal stresses of some ceramic/metallic FGM system [10,11]. In a most recent research, Bouchafa et al. have developed an analytical model which generated from the fabrication of exponential FGM (E-FGM) systems for the prediction of thermal residual stresses [12].

dispersed. In the FEM ANSYS analysis, the element type for the 2-D model was designed to be eight-node plane element (PLANE273). Moreover, fine meshes were introduced with a $0.1 \mathrm{~mm}$ element size to create 18, 910 nodes and 6, 200 elements for the cross sectioned model. Figure 2 illustrates (a) the boundary conditions and the element state used for the finite element analysis and (b) a schematic diagram of the 8 -node element configuration. The material properties of each layer of the FGM were calculated based on the values shown in Table 1. 


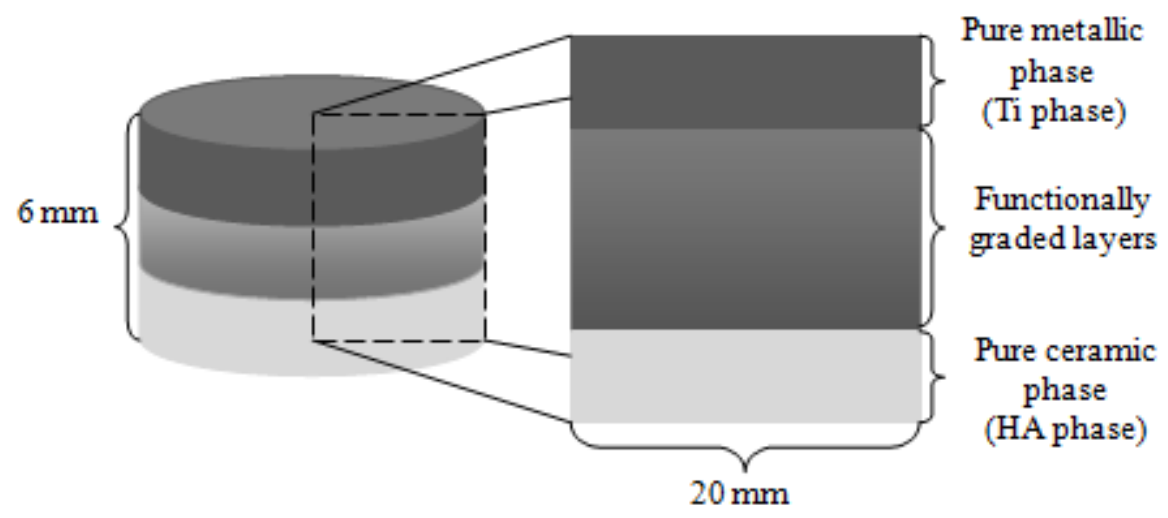

Figure 1. FGM 3-D geometry and the translation into 2-D geometry

Table 1. Conventional properties of hydroxyapatite and titanium materials for finite element analysis

\begin{tabular}{|c|c|c|c|}
\hline Material & Elastic Modulus, $E(\mathrm{GPa})$ & $\begin{array}{c}\text { Coefficient of Thermal } \\
\text { Expansion, } \alpha\left(10^{-6} /{ }^{0} \mathrm{C}\right)\end{array}$ & Poisson's ratio, $v$ \\
\hline $\mathrm{HA}$ & 110.89 & 14.87 & 0.28 \\
\hline $\mathrm{Ti}$ & 107.95 & 10.9 & 0.34 \\
\hline
\end{tabular}

(a)

Axial

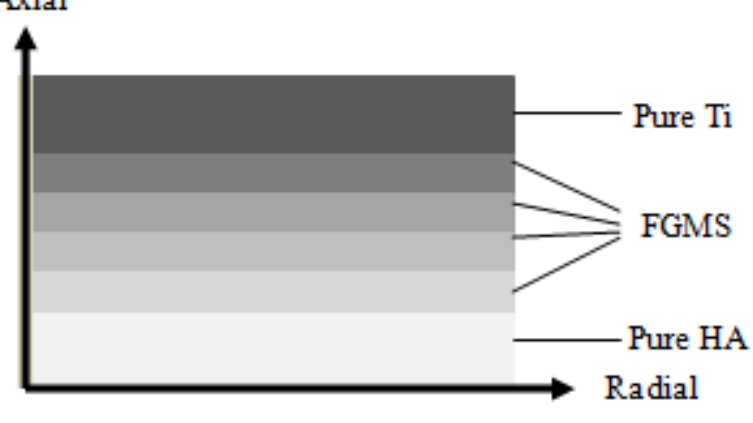

(b)

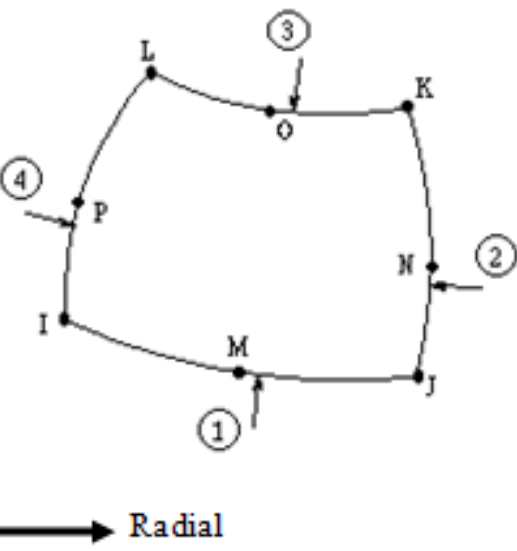

Element size: $1 \mathrm{~mm}$

Figure 2. (a) Element condition and boundary condition (b) 8-node geometry configuration

\subsection{Calculation of thermal residual stress}

The gradation of the elastic and thermal properties of the FGM is made based on an established mixture rule named linear rule of mixture. This analysis assumes ideal joining and dispersion between the composed materials by applying this rule. The linear rule of mixture equations for mechanical properties 
such as elastic modulus (E), Poisson's ratio (v) and coefficient of thermal expansion $(\alpha)$ of each layer calculation are shown as follows:

$$
\begin{array}{r}
E_{c}=V_{1} E_{1}+V_{2} E_{2} \\
\text { Eq. }(1) \\
\mathrm{v}_{c}=V_{1} \mathrm{v}_{1}+V_{2} \mathrm{v}_{2} \\
\text { Eq. }(2) \\
\alpha_{c}=V_{1} \alpha_{1}+V_{2} \alpha_{2}
\end{array}
$$

Ec, $v c$ and $\alpha c$ are the elastic modulus, Poisson's ratio and coefficient if thermal expansion (CTE) of the mixture, respectively whilst V1 and V2 represent the volume fractions of phases 1 and 2 . It should be noted that $\mathrm{V} 1+\mathrm{V} 2=1[9]$.

\subsection{Gradation Relation}

In order to see the relationship between the material properties and the direction or thickness of an FGM structure, the power law distribution of the volume fraction can be used [13]. For the optimization of the FGM structure, it is essential to get information on the effects of variations in the relative proportions of the elemental composition, on the residual stresses generated during processing. The following equation represents the gradually change of the material property through the thickness of an FG plate in terms of the volume fraction.

$$
\mathrm{P}(\mathrm{z})=\mathrm{P}_{\mathrm{c}}\left(\frac{2 \mathrm{z}+\mathrm{h}}{2 \mathrm{~h}}\right)^{\mathrm{n}}+\mathrm{P}_{\mathrm{m}}\left(1-\left(\frac{2 \mathrm{z}+\mathrm{h}}{2 \mathrm{~h}}\right)^{\mathrm{n}}\right) ;-\frac{\mathrm{h}}{2} \leq \mathrm{z} \leq \frac{\mathrm{h}}{2}
$$

Eq. (4) where $\mathrm{p}(\mathrm{z})$ represents a general material property at location $\mathrm{z}$ through the thickness, whereas $\mathrm{pc}$ and $\mathrm{pm}$ indicates the properties of the ceramic and metal elements in the plate, respectively. $\mathrm{n}$ refers to the grading index that dictates the material gradient through the thickness where for the case $\mathrm{n}=0$ denote a full ceramic region. The relation between the thickness and the total thickness of the structure can be seen as following:

$$
-\frac{\mathrm{h}}{2} \leq \mathrm{x}_{3} \leq \frac{\mathrm{h}}{2}
$$

where $\mathrm{x} 3$ indicates the thickness coordinate variable and $\mathrm{h}$ represents the total thickness of the plate. Moreover, in relation to $n, p \geq 0$ is defined as the volume fraction exponent or the grading index of the FGM structure.

\section{Results and discussion}

\subsection{Influence of the compositional distribution exponent}

The compositional distributions of the HA/Ti FGM structure with various compositional distribution exponent $(\mathrm{P})$ values are shown in Figure 3. In this study, the FGM structure was designed to be full ceramic at the one surface and full metallic at another surface. As can be seen in Figure 3, the volume fractions of the ceramic phase were varied along the structure thickness due to the compositional distribution exponent. 


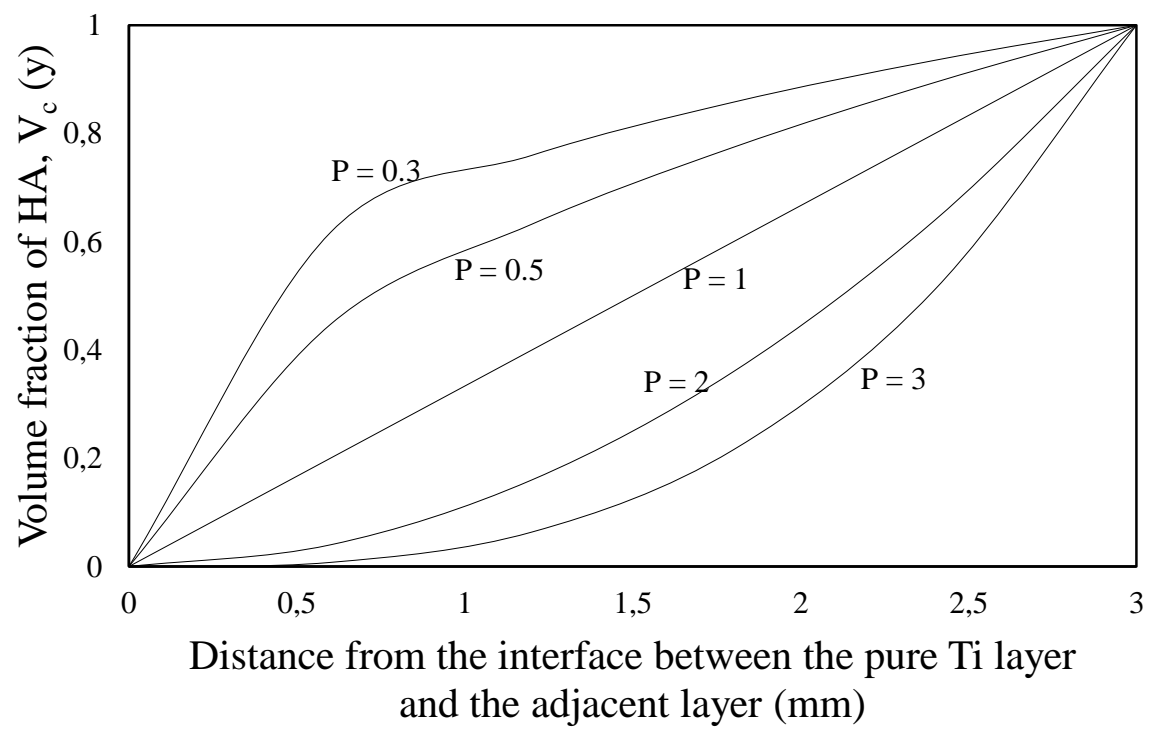

Figure 3. Compositional distribution profiles of HA/Ti FGMs by a variation of the power exponent $(\mathrm{P})$

The distribution of the residual thermal stresses in the $\mathrm{HA} / \mathrm{Ti}$ graded layers with different $\mathrm{P}$ calculated using some principal stress theories are indicated in Figure 4. Figure 4(a), (b) (c) and (d) show the distribution of von-Mises stress, first principal stress, second

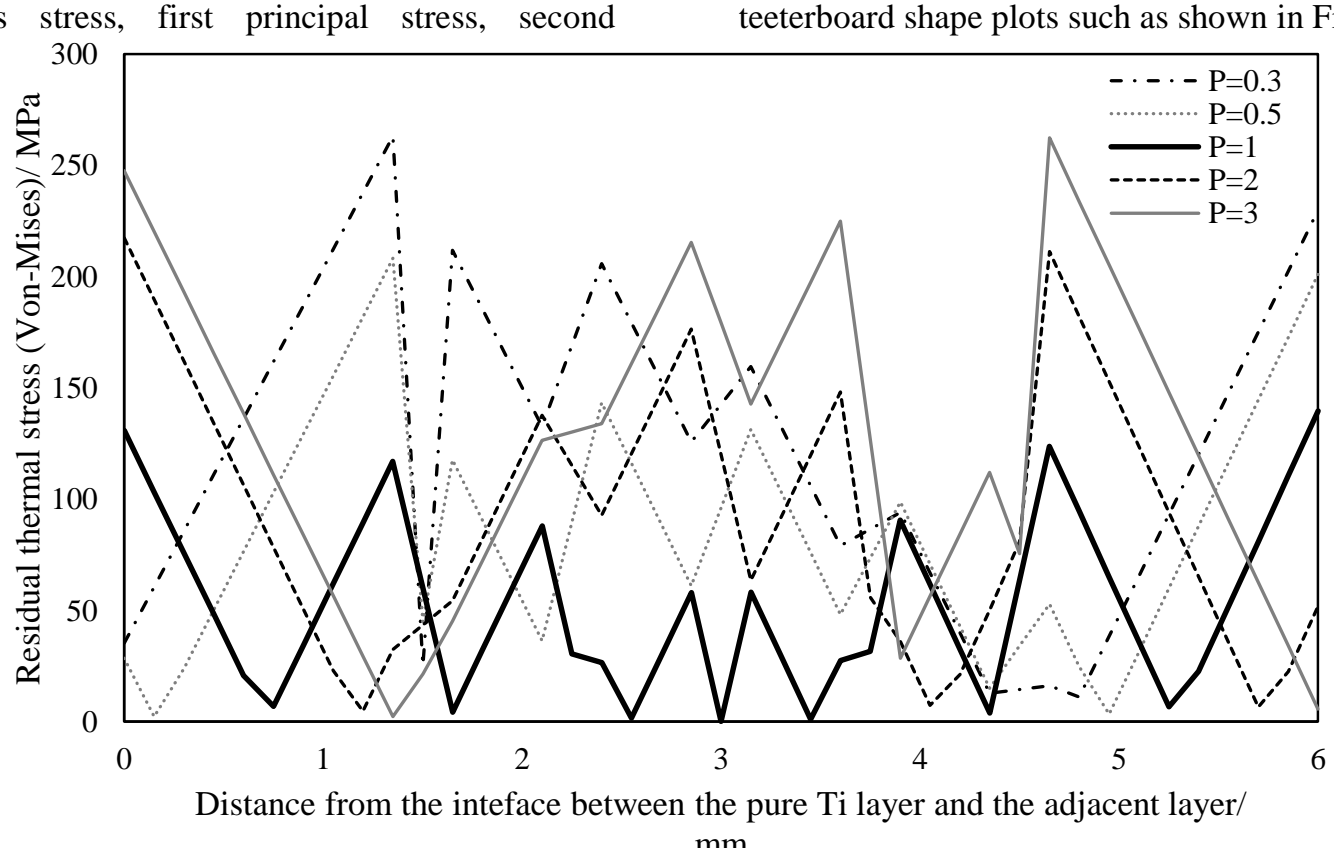

$\mathrm{mm}$

(a) Von-Mises stress principal stress and third principal stress along the various thickness of the HA/Ti FGM, respectively. The entire thermal residual stresses occurred within the FGM structure were characterized by the teeterboard shape plots such as shown in Figure 4. 


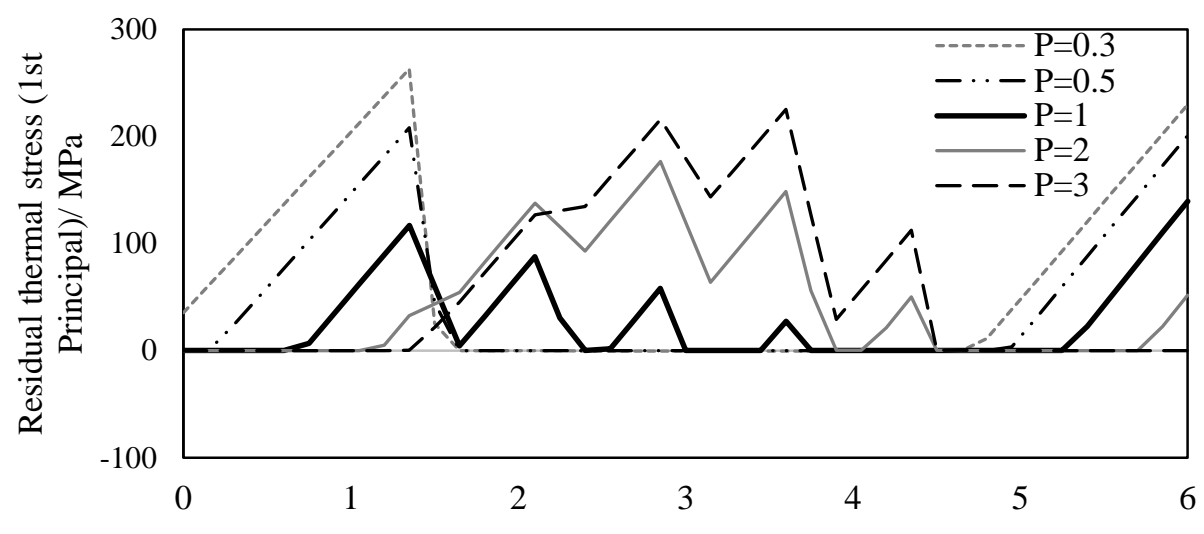

Distance from the interface between the pure Ti layer and the adjacent layer/ $\mathrm{mm}$

(b) $1^{\text {st }}$ Principal stress

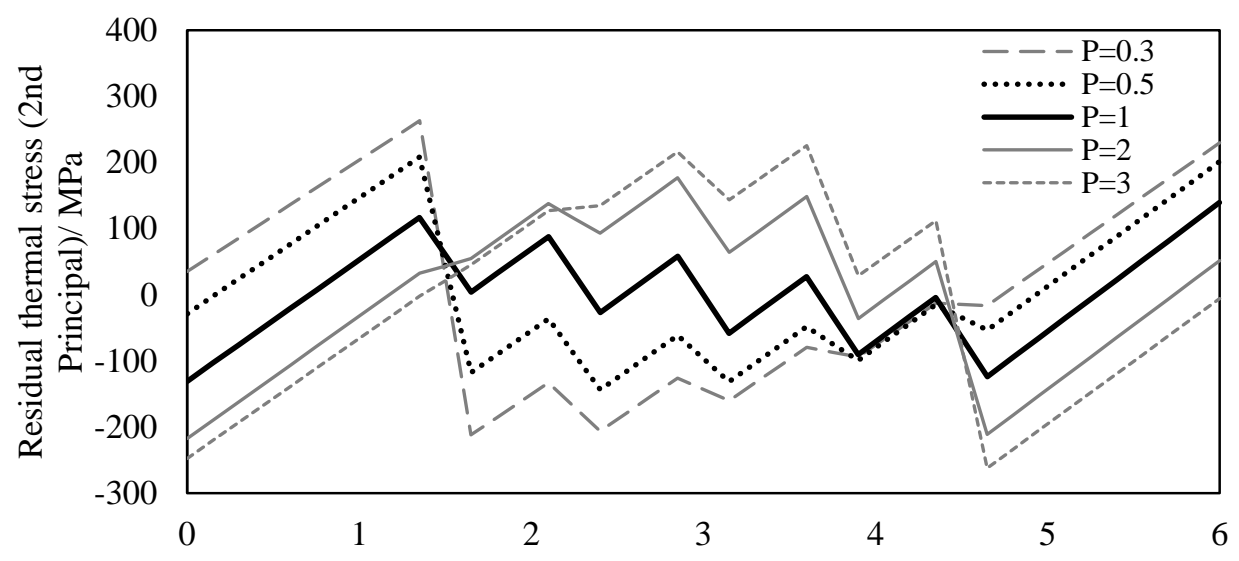

Distance from the interface between the pure Ti layer and the adjacent layer/ $\mathrm{mm}$

(c) $2^{\text {nd }}$ Principal stress

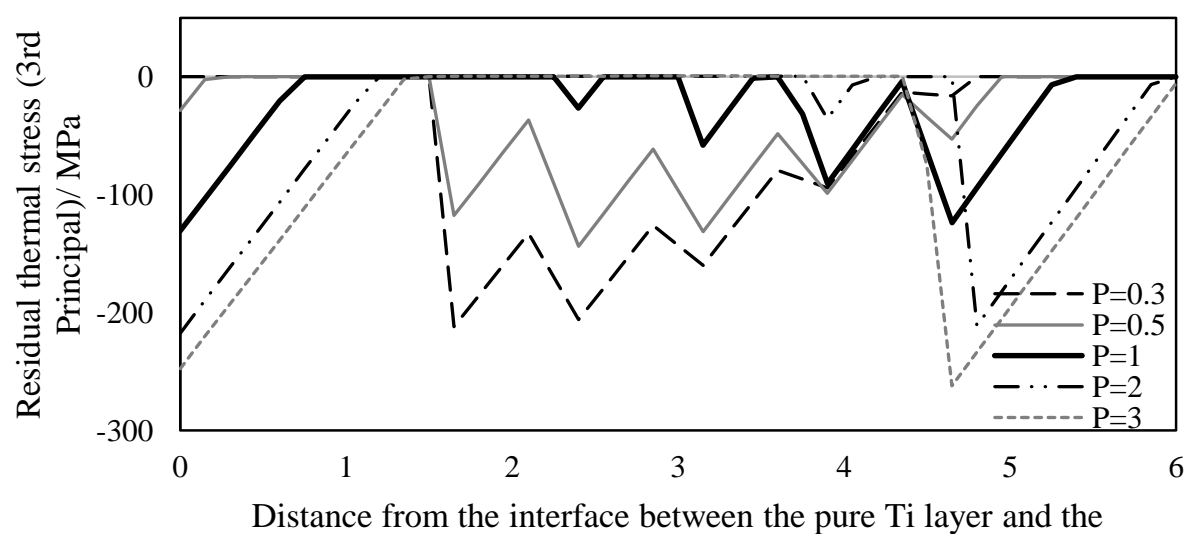
adjacent layer/ $\mathrm{mm}$

(d) $3^{\text {rd }}$ Principal stress 
Figure 4. Residual stress distributions of HA/Ti FGMs with various compositional distribution exponent $(\mathrm{P})(\mathrm{N}=6$, the thickness of pure Ti layer, middle graded layers and pure HA layer: $1.5 \mathrm{~mm}, 3 \mathrm{~mm}$ and $1.5 \mathrm{~mm}$ ).

In order overcome the limitations of pure HA (ceramic) and $\mathrm{Ti}$ (metallic) component, it is recommended to adjust the maximum thermal residual stress to be at the $\mathrm{HA} / \mathrm{Ti}$ intermediate transition layers as this region usually have the good thermal shock resistance and high strength [14]. Furthermore, the thermal residual stress should be minimized into the possibly smallest value. As can be seen in Figure 4, the distribution area of the maximum thermal stress varied gradually from the metallic phase layer to the ceramic phase layer within the increasing $\mathrm{P}$. This study found $\mathrm{P}=1$ as the optimum compositional distribution exponent for the designed HA/Ti FGM.

\subsection{Influence of the layer number}

The thermal residual stress distributions in the graded layers of the HA/Ti FGMs with various layer number have been calculated for this study. Table 2 shows the maximum thermal residual stresses of the FGMs and the maximum stress difference at the interface between the adjacent layers. The stress differences or stress jumps within the adjacent layers of the FGMs are taken into account in this evaluation according to the theory which said that the bigger layer number is beneficial for the better relaxation of the thermal residual stresses on the structure. This is also relates to the structure integrity where smoother change in the stress jump will leads to better properly bonding of the adjacent layers. Considering the reasonability of the workload and the practicability of the experiment, finding the optimized number of layer is enough to evaluate the effect of layer number on the FGM structure. Results from the finite element calculation indicate that the peak values of thermal residual as well as the peak values of the stress jump of the corresponding FGM structures are decreased gradually with the increasing layer number. Comparing these two values on each different layer number respectively, the maximum stress jumps are found decreased rapidly rather than the maximum thermal residual stresses. The simulation found the optimized layer number at $\mathrm{N} \geq 5$.

Table 2. Maximum thermal residual stress at the adjacent layers and maximum thermal stress difference of the HA/Ti FGM structures

\begin{tabular}{|c|c|c|}
\hline Model & $\begin{array}{c}\text { Maxumum residual } \\
\text { thermal stress (MPa) }\end{array}$ & $\begin{array}{c}\text { Maximum thermal stress } \\
\text { jump at the interfaces } \\
\text { between the adjacent layers } \\
\text { (MPa) }\end{array}$ \\
\hline 3 FGM Layers & 334 & 218 \\
\hline 4 FGM Layers & 222 & 116 \\
\hline 5 FGM Layers & 130 & 98.4 \\
\hline 6 FGM Layers & 123 & 86 \\
\hline 11 FGM Layers & 115 & 47.3 \\
\hline
\end{tabular}

\subsection{Influence of the thickness of FGM}

It is believed that instead of the grading index and the layer number, the thickness of the graded layers of an FGM also may influence the performance of the structure. For this study, the FGM layers with some different thickness have been simulated in order to find the optimum thickness range which is evaluated based on the residual thermal stress appearances. Figure 5 shows the residual thermal stress of the predesigned HA/Ti FGM model with various thicknesses of the graded layers. It can be seen that the maximum residual thermal stress initially decreased within the increasing thickness before it increased gradually. Explaining the plots trends, for thickness until 0.8 $\mathrm{mm}$, the residual thermal stress firstly is decreased from the peak tensile stress values to the lowest 
stress. The thermal stress then shows increment again. The thickness more than $0.8 \mathrm{~mm}$ show relaxation in the residual thermal stress within the FGM structure when the amount of increment and decrement of the values were found stable and maintain in certain values. Based on this observation, the optimum thickness range of the intermediate graded layers can be said is with $\pm 0.8 \mathrm{~mm}$.

For the results verification, the calculated residual thermal stresses of six layers of HA/Ti FGM were compared with the established values measured by
Chu et al. [15]. In the research, six layers of $\mathrm{Ha} / \mathrm{Ti}$ graded layers was fabricated and analyzed as an optimized structure for the application in biomedical usage. Figure 6 shows the comparison of the calculated stresses values with the actual or measured values reported by Chu et al. As the calculated values not spread far from the established values such as shown in Figure 6, so it can be said the finite element calculation is reliable. The results obtained from this analysis can be used as reference for the future works which is the preparation of the HA/Ti FGM specimens.

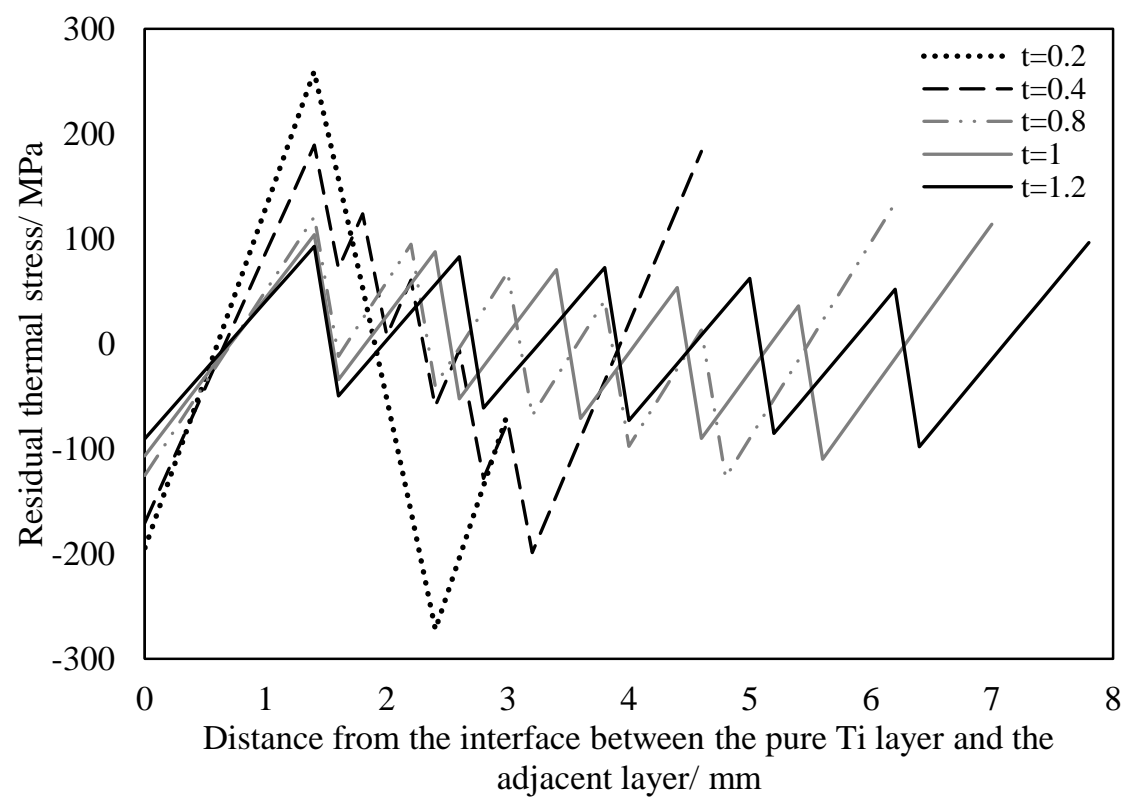

Figure 5. Residual thermal stress distributions of HA/Ti FGMs with various thicknesses of intermediate layers (N=6, $\mathrm{P}=1$, the thickness of pure Ti layer and pure HA layer: $1.5 \mathrm{~mm}$ and $1.5 \mathrm{~mm}$ ) 


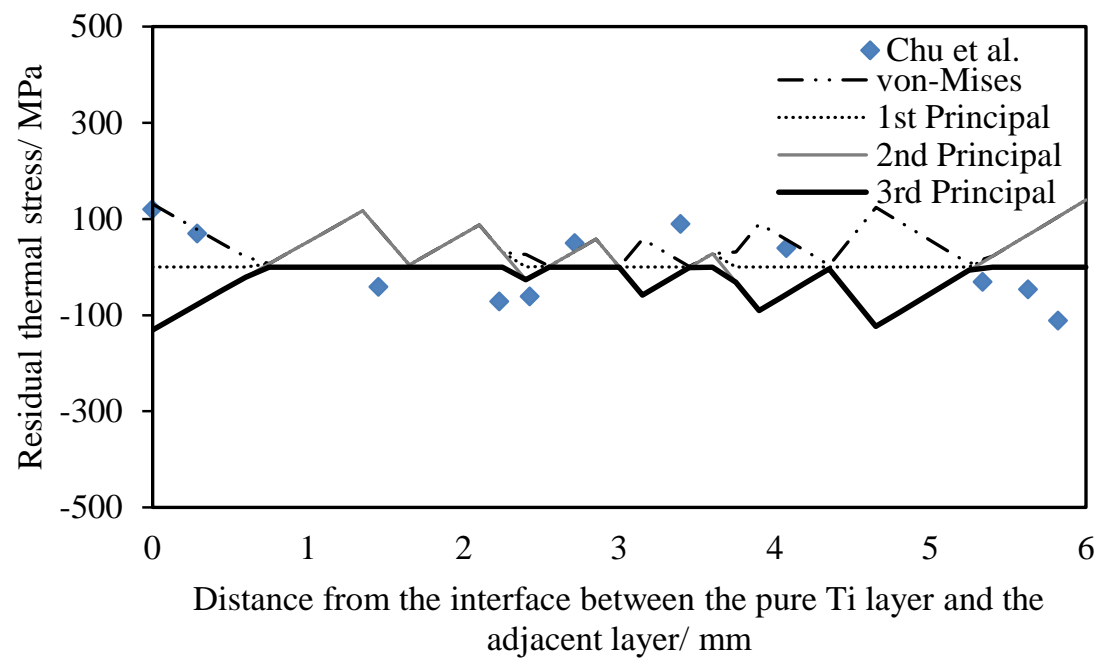

Figure 6. Comparison between the calculated and established values of thermal residual stresses of HA/Ti FGMs

\section{Conclusions}

From this study, it can be concluded that FGM structures are possibly modelled and designed using FEM. The outcomes from the parametric study proved that residual thermal stress which is believed occurred while cooling process during FGM fabrication can be analyzed by elastic finite element models. The compositional distribution exponent (P), the layer number $(\mathrm{N})$ and the thickness of the FGM adjacent layers $(t)$ were found influencing the residual thermal stresses of the HA/Ti FGM structures. $\mathrm{P}=1$ and $\mathrm{t}= \pm 0.8$ are the optimized values for the compositional distribution exponent and the adjacent FGM layer thickness, respectively. The study also concluded that the HA/Ti FGM should be constructed within at least 5 layers of gradually change in composition in order to reach a functional structure. For future work, it is planned to fabricate the HA/Ti FGM by following the optimized values for the verification through the comparison with the measured residual thermal stress values.

\section{Acknowledgements}

The authors would like to thank the Faculty of Manufacturing Engineering in University Malaysia Pahang (UMP) and University Malaysia Pahang for financial support under RDU1203124.

\section{References}

[1] Hirano T, Teraki J, and Yamada T. On the design of functionally gradient materials. In: Yamanouochi M, Koizumi M, Hirai T, Shiota I, editors. Proceedings of the 1st International Symposium on Functionally Gradient Materials, Sendai, Japan; 1990, p. 209-214. [2] Igari T, Notomi A, Tsunoda H, Hida K, Kotoh T, Kunishima S. Material properties of functionally gradient material for fast breed reactor. In: Yamanouochi M, Koizumi M, Hirai T, Shiota I, editors. Proceedings of the 1st International Symposium on Functionally Gradient Materials, Sendai, Japan; 1990, p.209-214.

[3] Mattei G, Tirella A, Ahluwalia A. Functionally Graded Materials (FGMs) with predictable and controlled gradient profiles: computational modelling and realisation. International Journal for Computational Methods in Engineering Science \& Mechanics (CMES) 2012;87(6):483-504.

[4] Tani J, Liu GR. Surface waves in functionally gradient piezoelectricplates. JSME International Journal Series A (Mechanics and Material Engineering) 1993;36:152-155.

[5] Hirano T, Whitlow LW, Miyajima M. Numerical analysis of efficiency improvement in functionally 
gradient thermoelectric materials. In: Holt JB, Koizumi M, Hirai T, Munir ZA, editors. Proceedings of the 2nd International Symposium on Functionally Gradient Materials, Ceram Trans, Westerville, Ohio;1993,p.23-30.

[6] Suresh S, Mortensen A. Fundamentals of Functionally Graded Materials. IOM Communications Ltd: London; 1998.

[7] Rabin BH, Williamson RL, Suresh S. Fundamentals of residual stresses in joints between dissimilar material. MRS Bull 1995;20:37-39.

[8] Park JH, Lee JC, Ryu SH, Jung KB, Song H-B, Yun JC, Choa YH, Ahn SH, Lee CS. Crack-free joint in a Ni-Al2O3 FGM system using three-dimensional modeling. Mater Trans 2009;50(7):1875-1880.

[9] Lee JC, Park JH, Ryu SH, Hong HJ, Riu DH, Ahn $\mathrm{SH}$, Lee CS. Reduction of functionally graded material layers for Si3N4-Al2O3 system using threedimensional finite element modeling. Mater Trans 2008;49(4):829-834.

[10] Sarikaya O, Celik E. Effects of residual stress on thickness and interlayer of thermal barrier ceramic
$\mathrm{MgO}-\mathrm{ZrO} 2$ coatings on $\mathrm{Ni}$ and $\mathrm{AlSi}$ substrates using finite element method. Mater. Des. 2002;23(7):645650.

[11] Chen F, Jie W. Finite element design of $\mathrm{MgO} / \mathrm{Ni}$ system functionally graded materials. J. Mater. Process. Technol. 2007;182(1-3):181-184.

[12] Boucafa A, Benzair A, Tounsi A, Draiche K, Mechab I, Bedia EA. Analytical modeling of thermal residual stresses in exponential functionally graded material system. Mater Design 2010;31:560-563.

[13] Reddy J, Wang C, Kitipornchai S. Axisymmetric bending of functionally graded circular and annular plates. Eur J Mech A-Solid 1999;18(2):185-199.

[14] Zhang G, Guo Q, Wang K, Zhang H, Song Y, Shi J, Liu L. Finite element design of $\mathrm{SiC} / \mathrm{C}$ functionally graded materials for ablation resistance application. Mater Sci Eng A 2008;488:45-49.

[15] Chu C, Zhu J, Yin Z, Lin P. Optimal design and fabrication of hydroxyapatite-Ti asymmetrical functionally graded biomaterial. Mater Sci Eng A 2003;348:244-250. 